Original Research Article

\title{
Prevalence and practice of self-medication among undergraduate medical students and non-medical students in south India
}

\author{
J. Sujit Ralin Daniel ${ }^{1 *}$, Prasanand S. ${ }^{1}$, Suba Joice ${ }^{2}$, Priscilla Jeba Rani ${ }^{3}$
}

\begin{abstract}
${ }^{1}$ Department of Pharmacology,
${ }^{2}$ Department of Community

Medicine, ${ }^{3}$ Department of

Physiology, Dr. SM CSI

Medical College \& Hospital,

Karakonam, Kerala, India

Received: 08 January 2019

Accepted: 04 February 2019

*Correspondence to:

Dr. J. Sujit Ralin Daniel,

Email: dr.ralin@gmail.com

Copyright: (C) the author(s), publisher and licensee Medip Academy. This is an openaccess article distributed under the terms of the Creative Commons Attribution NonCommercial License, which permits unrestricted noncommercial use, distribution, and reproduction in any medium, provided the original work is properly cited.
\end{abstract}

\begin{abstract}
Background: Self-medication is commonly practiced worldwide and the irrational use of drugs for self-medication is a major cause of concern. The situation is more complex when a number of prescriptions only medicines are used for self-medication which are easily available over the counter through pharmacies without any prescription. The objective of this study was to assess the prevalence and practice of self-medication among undergraduate medical students and non-medical students.

Methods: This cross-sectional questionnaire based study was carried out among 100 undergraduate students of a tertiary care medical college and 100 undergraduate students of an arts and science college in south India. The respondents were selected from the students who were present on the day of study. A pre-tested, self-assessing questionnaire was used to obtain the information on the prevalence and practice of self-medication.

Results: Self-medication was practiced by $96 \%$ and $92 \%$ of medical and nonmedical students respectively. Overall practice of self-medication was $94 \%$. Majority of females were self-medicating than males, $94 \%$ and $90 \%$ respectively. The most common symptom leading to self-medication among medical students were cough and common cold compared to headache among nonmedical students. The commonly used medicines for self-medication in both the groups were analgesics, antipyretics, cough suppressants and antibiotics. More number of medical students reported the use of antibiotics to treat infections (70\%) which was statistically significant.

Conclusions: The prevalence and practice of self-medication was alarming in both groups. The use of antimicrobials was also found to be very high among medical students. It is a need of the hour to create better awareness regarding the use of drugs for self-medication, to implement policies to prevent the dispensing of medicines without any prescription which would remain as the cornerstone for reducing the practice of self-medication.
\end{abstract}

Keywords: Medical, Non-medical, Respondents, Self-assessing questionnaire, Self-medication

\section{INTRODUCTION}

Self-medication is defined by the World Health Organisation (WHO) as "use of medicinal products by the consumer to treat self-recognized disorders or symptoms, the intermittent or continued use of a medication previously prescribed by a physician for chronic or recurring disease or symptom, or the use of medication recommended by lay sources or health workers not entitled to prescribe medicine". ${ }^{1}$ Medicines for self-medication are called non-prescription medicines or "over the counter" (OTC) medicines. These medicines are designed and labelled for use without medical supervision and are approved as safe and effective for such use. ${ }^{2}$

Self-medication is fairly a common practice and when practised correctly, self-medication has a positive impact on individual and healthcare systems. It allows patients to 
take responsibility and build confidence to manage their own health, thereby, promoting self-empowerment. ${ }^{3}$ The WHO promotes the practice of self-medication for effective and quick relief of symptoms without medical consultation. This will reduce burden on healthcare services, which are often understaffed and inaccessible in rural and remote areas.

However, inappropriate self-medication results in irrational use of drugs, wastage of resources, increase resistance of pathogens and entails serious health hazards such as adverse drug reactions, risk of drug interactions and drug dependence. ${ }^{4}$ Self-medication patterns are influenced by many factors such as age, gender, income and expenditure, education level and medical knowledge. An increase in chronic diseases, lack of health services, poverty, increased media exposure and extensive advertisement of pharmaceutical products could be listed for the risk of self- medication. ${ }^{4,5}$ Self-medication can be practised and is appropriate for short-term relief of symptoms where accurate diagnosis is not needed and in uncomplicated cases of some chronic and recurrent diseases. $^{6}$ However, irrational use of medicines, in particular self-medication with antibiotics, has been widely reported leading the WHO to call for attention to the dangers of self-medication as a cause of antimicrobial resistance. $^{7}$

It is now evident that self-medication is widely practised in both developing and developed countries. India also faces the problem of inappropriate use of self-medication in significant number. ${ }^{8}$ According to drug laws applicable to India, self-medication is permitted for OTC drugs, but there is no specific list of OTC drugs in India. The situation is more complex when a number of prescription only medicines are used for self-medication which are easily available through pharmacies without any prescription. The increasing practice of self-medication requires more and better education of both the public and health professional to avoid the irrational use of drugs. ${ }^{9}$ Hence this study was planned to assess the prevalence and practice of self-medication among undergraduate medical and non-medical students.

\section{METHODS}

This cross-sectional questionnaire based study was conducted after obtaining approval from the institutional ethics committee. The aim of this study is to assess the prevalence and practice of Self-medication among undergraduate medical students and non-medical students. The study subjects were medical students from a tertiary care medical college and non-medical students from an arts and science college in south India. Those who were willing to participate in the study and age of the respondents between 18 years and 22 years were included in the study. Students who were receiving long term prescribed medications and those who were not willing to give written informed consent were excluded from the study.
A total of 200 students (100 medical and 100 non-medical students) fulfilling the inclusion criteria were enrolled into the study after obtaining a written informed consent. The purpose of the study was well explained and confidentiality of the participants was ensured. A selfstructured, pre-tested questionnaire was used to obtain the information on demographics, knowledge and their practice of self-medication. Any event of use of over the counter or prescription only medicines without a doctor's prescription was considered as self-medication.

\section{Statistical analysis}

The data was analyzed and categorized in counts and percentages. The association between qualitative variables was tested by Chi-square test. p value less than 0.05 was considered statistically significant.

\section{RESULTS}

A total of 200 students completed the self-medication study questionnaire. The socio-demographic profile of the respondents is shown in Table 1.

Table 1: Socio-demographic profile of respondents.

\begin{tabular}{|llll|}
\hline & & $\begin{array}{l}\text { Medical } \\
\text { students } \\
\text { (n=100) } \\
\text { Group 1 }\end{array}$ & $\begin{array}{l}\text { Non-medical } \\
\text { students } \\
\text { (n=100) } \\
\text { Group 2 }\end{array}$ \\
\hline Age (years) & & $20 \pm 2.23$ & $19 \pm 1.34$ \\
\hline \multirow{2}{*}{ Gender } & Male & $44(44 \%)$ & $48(48 \%)$ \\
\hline \multirow{2}{*}{ Residence } & Female & $56(56 \%)$ & $52(52 \%)$ \\
\cline { 2 - 4 } & Urban & $76(76 \%)$ & $63(63 \%)$ \\
\hline
\end{tabular}

Age expressed as Mean age $( \pm \mathrm{SD})$. Other values expressed as counts and percentages

In group I (medical students), 44\% were men and $56 \%$ were women while in group II (non-medical students), $48 \%$ were men and $52 \%$ were women. Mean age $( \pm$ SD) of the respondents was $20 \pm 2.23$ years in group I and $19 \pm 1.34$ years in group II. In group I, $76 \%$ of respondents were from urban background and $24 \%$ were from rural areas. Similarly, in group II, $63 \%$ of respondents have an urban background and $37 \%$ from rural areas.

Self-medication was practiced by $96 \%$ respondents from group I and $92 \%$ respondents from group II. A proportionately larger number of females were selfmedicating than males, $94 \%$ and $90 \%$ respectively. The difference between the two groups was not statistically significant. The overall practice of self-medication was $94 \%$ from both the groups.

The practice of self-medication among respondents from both the groups is mentioned in Table 2. About $74 \%$ of respondents in group I and $66 \%$ of respondents in group II practiced a combination of two or more drugs for selfmedication and there was no statistically significant 
difference between the two groups. $28 \%$ of respondents from both the groups said yes, when asked whether they remember the correct dose of drugs used for selfmedication. $66 \%$ respondents from group I and $72 \%$ respondents from group II mentioned that they did not remember the correct dose. $84 \%$ of medical students and $73 \%$ of non-medical students mentioned that they check the expiry date of medicines before using them as selfmedication.

Table 2: Practice of self-medication in both the groups.

\begin{tabular}{|c|c|c|c|}
\hline & Response & $\begin{array}{l}\text { Medical students } \\
(\mathrm{n}=100) \text { Group } 1\end{array}$ & $\begin{array}{l}\text { Non-medical students } \\
(\mathrm{n}=100) \text { Group } 2\end{array}$ \\
\hline $\begin{array}{l}\text { Frequency of combining two or more drugs for } \\
\text { self-medication }\end{array}$ & Yes & $74(74 \%)$ & $66(66 \%)$ \\
\hline \multirow{4}{*}{$\begin{array}{l}\text { Remembering dose of medicines used for self- } \\
\text { medication }\end{array}$} & No & $26(26 \%)$ & $34(34 \%)$ \\
\hline & Yes & $28(28 \%)$ & $28(28 \%)$ \\
\hline & No & $66(66 \%)$ & $72(72 \%)$ \\
\hline & Not Sure & $06(6 \%)$ & 00 \\
\hline \multirow[t]{3}{*}{$\begin{array}{l}\text { Checking of expiry date of medicines used for } \\
\text { self-medication }\end{array}$} & Yes & $84(84 \%)$ & $73(73 \%)$ \\
\hline & No & 00 & $06(6 \%)$ \\
\hline & Not Sure & $16(16 \%)$ & $21(21 \%)$ \\
\hline \multirow[t]{2}{*}{$\begin{array}{l}\text { Experience of adverse effects with self- } \\
\text { medication }\end{array}$} & Yes & $12(12 \%)$ & $16(16 \%)$ \\
\hline & No & $88(88 \%)$ & $84(84 \%)$ \\
\hline
\end{tabular}

In group I, $12 \%$ and in group II, $16 \%$ of the respondents mentioned that they have experienced adverse drug reactions with self-medication and all the respondents in group I who have suffered from side effects consulted doctor because of the adverse drug reactions and in group II, $11 \%$ of the respondents consulted doctor because of adverse drug reactions.

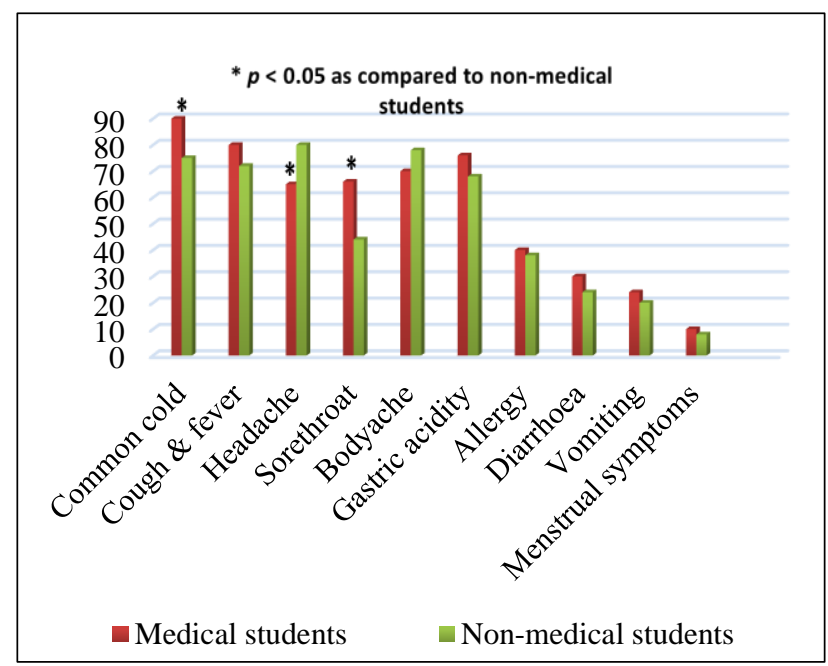

Figure 1: Symptoms leading to self medication in both the groups.

The indications or symptoms leading to self-medication as reported by respondents in group I and II is shown in Figure 1. Common cold, fever and cough, headache, sore throat and body ache were the common indications leading to self-medication. $90 \%$ respondents from group I have reported common cold as the most common symptom leading to self-medication, whereas in group II, majority of students $(80 \%)$ have reported headache as the most common symptom. The practice of self-medication for common cold and sore throat was statistically significant in group I and self-medication for headache was statistically significant in group II.

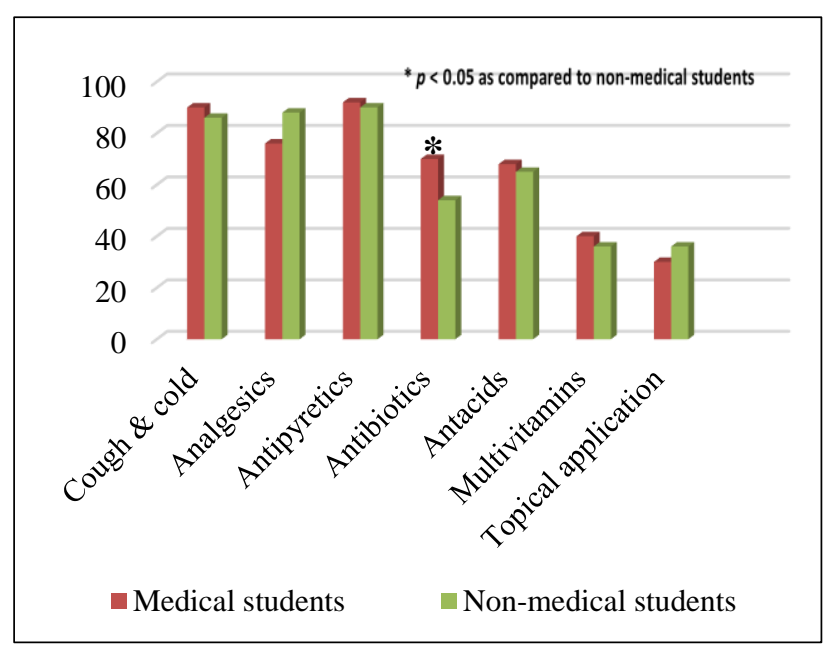

Figure 2: Drugs used by the respondents in both the study groups.

The medicines/drugs most commonly used for selfmedication are shown in Figure 2. Antipyretics, analgesics 
and cough and cold remedies were the most commonly used medications for self-medication. $70 \%$ of respondents in group I reported the use of antibiotics to treat infections which was statistically significant.

Respondents from both the groups have mentioned family (70\% and $64 \%$ respectively) as the main source of medicines for self-medication. In group II statistically significant number of respondents (44\%) mentioned pharmacist also as main source of medicines for selfmedication as shown in Figure 3.

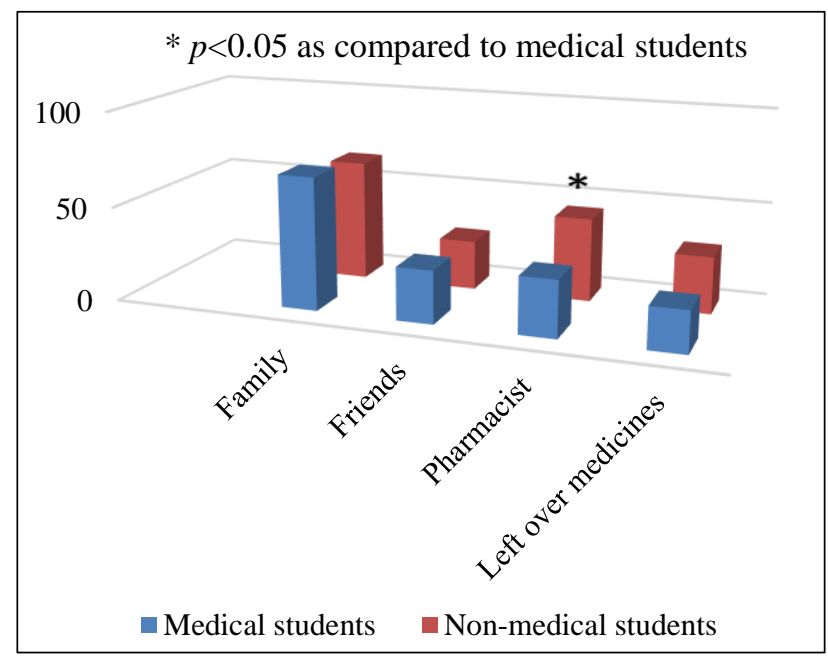

Figure 3: Sources of medicines for self-medication.

\section{DISCUSSION}

Self-medication is the selection and use of medicines by individuals to treat self-recognized illnesses or symptoms. Self-medication by itself has both pros and cons that depend on the person who takes self-medication and what he chooses to self-medicate. ${ }^{10}$

In this study we have researched the prevalence and practice of self-medication among medical and nonmedical students in south India. Various studies in India and different parts of the world have reported the practice of self-medication among medical as well as non-medical students. ${ }^{11,12}$ In the present study the prevalence of selfmedication was $96 \%$ among medical students and $92 \%$ among non-medical students.

Prevalence of self-medication among the medical students in India varies between $71 \%$ and $92 \%$ (Badiger et al, 2012). ${ }^{13,14}$ This study results show a slightly higher prevalence of self-medication among medical students. Prevalence of self-medication in non-medical students also shows a wide variation, ranging from $56.90 \%$ to $98 \% .^{15,16}$ Even in the general population a wide variation in the prevalence of self-medication ranging from $12.7 \%$ in Spain to $95 \%$ in Harare has been reported. ${ }^{17,18}$ Hence, it is difficult to compare the results in different populations and this could be because of the differing socio-economic profiles, literacy levels and demographic characteristics and also because of different methodologies used to find out the prevalence of self-medication.

Similar to many other studies on self-medication fever, pain (headache and body ache) and cough and cold were the most common symptoms leading to self-medication in both the groups. ${ }^{3,14,19}$ It is reported that in studies conducted among first year medical students, headache was the most common symptom for self-medication (70.9\%) followed by cough/common cold, stomachache, and fever. ${ }^{17}$ Another study has also reported headache $(72.4 \%)$ as the most common morbidity among medical students seeking medication in Karachi. ${ }^{19}$ In a study conducted in Ethiopia, fever and headache were the most commonly reported symptoms for self-medication followed by cough and common cold..$^{20}$

Our study results are well comparable with these studies showing that fever, headache and body aches and cough and cold are the common indications leading to selfmedication among medical and non-medical students. This correlates well with the fact that analgesics and antipyretics are the drugs most commonly used for selfmedication. In addition to this, our study showed a significantly higher number of medical students (group I) reporting sore throat/ pharyngitis also a common cause for self-medication.

The drugs which were frequently used for self-medication in our study were antipyretics, analgesics and cough and cold remedies in both the groups. Several other studies on self-medication also describe this pattern of selfmedication among students. ${ }^{14,17,19,21}$ In the study conducted in Karachi, ${ }^{19}$ analgesics were the most common $(88.3 \%)$ drugs for self-medication followed by antipyretics and antibiotics; the study in Bahrain (2006) also reported analgesics to be the most commonly used drugs $(81.3 \%)$ for self-medication. ${ }^{17}$ Our study results are comparable to these studies.

In contrast to some other studies, this present study results show that a significantly higher number of medical students have reported the use of antibiotics as selfmedication to treat sore throat/ pharyngitis. A study from Bahrain reported that antibiotics contributes only to $6 \%$ of self-medication. ${ }^{17}$ The reason for limited use of antibiotics for self-medication among medical students as reported in another study is that the governments in these countries where the studies are conducted have strict regulatory policies about the prescription and over the counter sale of antibiotics. $^{22}$

The reports available about the use of antimicrobials as self-medication are very inconsistent. Certain studies (Kaur et al, Banerjee et al, Zafar et al) report a higher use of antibiotics as self-medication to treat infections. ${ }^{14,19,21}$ Our study results are consistent with these studies conducted in developing countries. This happens mostly because of the free access and easy availability of antibiotics as over the counter drugs in many developing 
countries. The practice of using antimicrobials as selfmedication has serious consequences of antimicrobial resistance as mentioned by the WHO. It is evident from many studies that countries with strict rules and regulations concerning the prescription and over the counter sale of antibiotics have limited usage of antibiotics. It is also evident from our study that a significant number of respondents from both the groups practice polypharmacy which in turn may lead to drug interactions and serious adverse effects.

Majority of students from both the groups in this survey have stated the family as the most common source of medicines for self-medication. A statistically significant number of non-medical students have conveyed pharmacists also as the chief source for procuring medicines without prescription. This similar trend is also noted in another study (Kaur et al) from India. ${ }^{21}$ This also implies that pharmacists should be trained to some extent on symptomatic management of minor illness rather than just managing pharmacies and product selling.

\section{CONCLUSION}

To conclude, there is no doubt about the role of selfmedication in the healthcare services. Nevertheless, selfmedication has to be within the scope and it ought to have restrictions to the kind of symptoms to be self-diagnosed and treated. The prevalence and practice of self-medication in our study was alarming in both groups. Fever, headache, cough and cold were the most common indications leading to self-medication. Antipyretics and analgesics were the most commonly used medicines for self-medication. The use of antibiotics was also found to be very high among medical students. This creates a concern over the antibiotic use among the medical students and doctors because of their medical knowledge about drugs and diseases, which could also contribute to antimicrobial resistance. It is the need of the hour to create better awareness among medical and non-medical population regarding the use of drugs for self-medication, to implement strategies and guidelines to prevent the dispensing of medicines without any prescription which would remain as the cornerstone for reducing the practice of self-medication.

\section{ACKNOWLEDGEMENTS}

Authors would like to thank the study participants who voluntarily took part in the study.

Funding: No funding sources Conflict of interest: None declared

Ethical approval: The study was approved by the Institutional Ethics Committee

\section{REFERENCES}

1. World Health Organization. Guidelines for the regulatory assessment of medicinal products for use in self-medication, 2000 Available at:
http://apps.who.int/medicinedocs/en/d/Js2218e/.

Accessed on 5 December 2018.

2. Abdelmonein SA, Eman R, Hussain A. Selfmedication practice among diabetic patients in Kuwait. Med Princ Pract. 2008;17:315-20.

3. Hughes CM, McElnay JC, Fleming GF. Benefits and risks of self-medication. Drug Saf. 2001;24:1027-37.

4. Kiyingi KS, Lauwo JA, Drugs in home: Danger and waste. World Health Forum. 1993;14:381-4.

5. World Health Organisation (WHO). The use of essential drugs. World Health Organ Tech Rep Ser. 1983;685:44-5.

6. Bennett PJ, Brown MJ. Topics in drug therapy. In Bennett PJ, Brown MJ, editors. Clinical Pharmacology.10th ed. New York: Churchill Livingstone; 2008:5-32.

7. Kamat VR, Mark N. Pharmacies: self-medication and pharmaceutical marketing in Bombay, India. Soc Sci Med. 1998;47:779-94.

8. Nalini GK. Self-medication among allopathic doctors in Karnataka, India. BJMP. 2010;3:325.

9. Worku S, Abebe M. Practice of self-medication in Jimma Town. Ethiop J Health Dev. 2003;17:111-16.

10. Dangers of Self Medication. Available: http://www.healthguidance.org/entry/15933/1/Danger s-of-Self-Medication.html. Accessed on 5 December 2018.

11. Sontakke SD, Bajait CS, Pimpalkhute SA, Jaiswal KM, Jaiswal SR. Comparative study of evaluation of self-medication practices in first and third year medical students. Int J Biol Med Res. 2011;2(2):5614.

12. Kumar N, Kanchan T, Unnikrishnan B, Rekha T, Mithra P, Kulkarni V, et al. Perceptions and Practices of Self-Medication among Medical Students in Coastal South India. PLoS ONE. 2013;8(8):e72247.

13. Badiger S, Kundapur R, Jain A, Kumar A and Pattanshetty S. Self-medication patterns among medical students in South India. Australasian Med J. 2012;5(4):217-220.

14. Banerjee I, Bhadury T. Self-medication practice among undergraduate medical students in a tertiary care medical college, West Bengal. J Postgrad Med. 2012;58(2):127-31.

15. Sawalha AF. A descriptive study of self-medication practices among Palestinian medical and nonmedical university students. Res Social Adm Pharm. 2008;2:164-72.

16. Figueiras A, Caamano F, Gestal OJJ. Sociodemographic factors related to self- medication in Spain. Eur J Epidemiol. 2000;16(1):19-26.

17. James H, Handu SS, Khaja KA, Sequeira RP. Influence of medical training on self-medication by students. Int J Clin Pharmacol Ther. 2008;46(1):23-9.

18. Kasilo OJ, Nhachi CF, Mutangadura EF: Epidemiology of household medications in urban Gweru and Harare. Cent Afr J Med. 1991;37(6):16771.

19. Zafar SN, Syed R, Waqar S, Zubairi AJ, Vaqar T, Shaikh M, et al. Self-medication amongst university 
students of Karachi: prevalence, knowledge and attitudes. J Pak Med Assoc. 2008;58(4):214-7.

20. Abay SM, Amelo W. Assessment of self-medication practices among medical, pharmacy, and health science students in Gondar University, Ethiopia. J Young Pharm. 2010;2:306-10.

21. Kaur R, Badyal DK. Knowledge, Attitude and practice of self-medication among non-medical staff of a medical and non-medical institute. Clin Res. 2013;5(2):31-9.
22. Henry J, Handu SS, Khalid AJ, Khaja ASO, Sequeira RP. Evaluation of the knowledge, attitude and practice of self-medication among first-year medical students. Med Princ Pract. 2006;15:270-5.

Cite this article as: Daniel JSR, Prasanand S, Joice S, Rani PJ. Prevalence and practice of selfmedication among undergraduate medical students and non-medical students in south India. Int J Basic Clin Pharmacol 2019;8:388-93. 